\title{
A TEMÁTICA AMBIENTAL EM ESCOLAS PÚBLICAS NO AMAZONAS: ANÁLISE A PARTIR DE PROJETOS DESENVOLVIDOS NO ÂMBITO DO PROGRAMA CIÊNCIA NA ESCOLA - PCE
}

Karina de Oliveira Milhomem ${ }^{1}$ Maria Olivia de Albuquerque Ribeiro Simão ${ }^{2}$

Resumo: Acreditamos que a educação se constitui como uma poderosa ferramenta de intervenção no mundo para a construção de novos conceitos e consequente mudança de hábitos. O objetivo deste trabalho consistiu em averiguar a presença da temática ambiental nas escolas públicas do Amazonas no âmbito do Programa Ciência na Escola - PCE, que é um programa de incentivo à iniciação científica para estudantes da educação básica e é mantido pela Fundação de Amparo à Pesquisa do Estado do Amazonas - FAPEAM. Foram analisados projetos que traziam a temática ambiental como objeto de pesquisa. Os resultados aqui apresentados foram obtidos a partir da análise de editais, decisões, projetos e seus respectivos relatórios. Pôde-se observar que esta temática não é prioridade nos projetos desenvolvidos, pois somente $8 \%$ deles, nos anos de 2014 e 2015, trouxeram esta abordagem como tema de pesquisa.

Palavras-chave: Educação Ambiental; Projetos Escolares; Ensino Formal.

1 Mestre em Ciências do Ambiente e Sustentabilidade na Amazônia (PPGCASA/UFAM). Professora do quadro efetivo da Secretaria de Educação e Qualidade de Ensino do Amazonas - SEDUC. E-mail: karinamilhomem@hotmail.com

2 Doutora em Biologia de Água Doce e Pesca Interior (BADPI/INPA). Professora do Departamento de Biologia da Universidade Federal do Amazonas - UFAM. E-mail: mariaoliviar@uol.com 


\section{Introdução}

Nos dias de hoje, a temática ambiental tem sido bastante frequente nas discussões de diversos grupos sociais. A análise crítica dos danos causados ao ambiente e da dinâmica do contexto social ao longo da história, que se conformaram na crise ambiental e civilizatória que temos, é imprescindível no contexto escolar. É necessário despertar nestes jovens em formação inquietações que visem à mudança de hábitos e ao desenvolvimento de habilidades a fim de reverter o quadro atual.

A educação escolar se constitui como a mais poderosa de todas as ferramentas de intervenção para a construção de novos conceitos, desenvolvimento de consciência crítica e reflexão para consequentes mudanças. É também o instrumento de construção do conhecimento e a forma com que todo o desenvolvimento intelectual conquistado é passado de uma geração à outra, permitindo, assim, a máxima comprovada de que cada geração avança um passo em relação à anterior no contexto geral e, sobretudo, no campo do conhecimento científico (CUBA, 2010).

No final do século XX, a Educação Ambiental (EA) surgiu como alternativa no processo educacional, voltada para elaboração de uma nova visão de mundo e de práticas sociais capazes de minimizar os impactos ambientais ocorrentes. Assim, a EA visa à formação de cidadãos críticos, conscientes e atuantes, na promoção de uma educação política (Reigota, 1994). No Brasil, a partir da década de 90 , ocorre o incentivo à promoção de educação de qualidade, crítica, a fim de tornar o cidadão capaz de entender tais modificações e intervir na promoção de mudanças na racionalidade, por meio da implementação de propostas e programas governamentais voltados para as escolas e para a promoção da EA, dentre eles: Parâmetros Curriculares Nacionais - PCNs (Brasil, 1998); Programa Nacional de Educação Ambiental - PNEA (Brasil, 1999); Comissão de Meio Ambiente e Qualidade de Vida - COMVIDA (Brasil, 2004); Programa Vamos Cuidar do Brasil com as Escolas - PVCBE (Brasil, 2007); Programa Nacional de Educação Ambiental - ProNEA (Brasil, 2014); Plano Nacional de Educação 2014-2024 (Brasil, 2014); Objetivos do Desenvolvimento Sustentável 2030 (ONU, 2015).

Considerando o estabelecido nas Diretrizes Curriculares Nacionais para a Educação Ambiental (BRASIL, 2012), este processo educacional é desenvolvido por meio de três modalidades básicas: disciplinas especiais, inserção da temática ambiental nas disciplinas e projetos. Tajber \& Mendonça (2006), na publicação $O$ que fazem as escolas que dizem que fazem Educação Ambiental, onde analisam o cenário de escolas públicas brasileras, identificaram que, no período de 2001 a 2004, ocorreu aumento na inserção da temática ambiental nas disciplinas, seguida da modalidade de projetos e que as ações se concentravam nas disciplinas geografia e ciências. Segundo Hernandez e Ventura (1994), trabalhar com projetos traz uma nova perspectiva para entendermos o processo ensino-aprendizagem. Aprender deixa de ser um 
simples ato de memorização e ensinar não significa mais repassar conteúdos prontos (NOGUEIRA, 2001; HERNANDEZ, 1998).

Neste contexto, o Programa Ciência na Escola - PCE surge como política pública voltada para o envolvimento de estudantes e professores da educação básica de escolas públicas do Amazonas em atividades de pesquisa nas mais diversas temáticas, a partir de incentivos financeiros. O PCE foi criado em 2004, por uma iniciativa da Fundação de Amparo à Pesquisa do Estado do Amazonas - FAPEAM, em parceria com órgãos públicos executores das políticas de educação no Amazonas: Secretaria de Estado da Educação e Qualidade do Ensino - SEDUC e Secretara Municipal de Educação de Manaus - SEMED. Voltado exclusivamente para professores de escolas públicas das redes municipal e estadual de ensino que estejam atuando em sala de aula nas disciplinas do Ensino Fundamental, Médio e Educação de Jovens e Adultos, o PCE incentiva a aproximação da ciência ao ambiente escolar. Nos projetos aprovados, são custeadas bolsas mensais para: o professor coordenador (Professor Jovem Cientista, com valor de $\mathrm{R} \$ 461,00$ ); um profissional de apoio técnico ( $R \$ 360,00)$ e cinco estudantes (Iniciação Cientifica Júnior, $R \$ 120,00$ cada). Além das bolsas, a FAPEAM aporta recursos financeiros para custear as despesas com a execução do projeto (auxílio-pesquisa) no valor de até $R \$$ $4.840,00$ por projeto.

Neste trabalho, analisamos como a temática ambiental está sendo abordada em projetos apoiados pelo PCE, desenvolvidos em escolas públicas no Estado do Amazonas, nos anos de 2014 e 2015.

\section{Metodologia}

Esta pesquisa teve uma abordagem qualitativa (GIL, 2010), de caráter descritivo e analítico. Foram analisados os projetos aprovados nos Editais PCE FAPEAM N. 029/2013 e N. 021/2014, arquivados em mídia digital no Banco de Dados da Agência. A partir de uma lista de 763 projetos fornecida pela Fundação, foram identificados 61 projetos que abordaram questões ambientais, dos quais foram solicitadas cópias, juntamente com os respectivos relatórios finais. A partir da leitura desses projetos e seus relatórios, foram registradas em planilha Excel as seguintes informações: título do projeto; escola de vínculo do coordenador; município de localização e sistema educacional de vinculação da escola (estadual ou municipal); valores aportados (bolsas e auxílio pesquisa); formação do coordenador; abrangência de atuação (escola, comunidade, etc.); público-alvo (alunos, professores, outros servidores da escola, comunidade, etc.); tema; enfoque dado ao tema abordado; atividades desenvolvidas; principais resultados obtidos e dificuldades enfrentadas. 


\section{Resultados e discussão}

No âmbito desses editais, foram aprovados e homologados 763 projetos, desenvolvidos em escolas públicas das redes estadual (SEDUC) e municipal (SEMED) de educação localizadas na capital e no interior (Tabela 1).

Tabela 1: Número de projetos previstos e aprovados pelo Conselho Diretor da FAPEAM (Decisões do Conselho Diretor FAPEAM N. 062/2014 e N. 117/2015) nos Editais N. 029/2013 e N. 021/2014 - PCE/FAPEAM/SEDUC/SEMED para serem desenvolvidos nos anos 2014 e 2015.

\begin{tabular}{|c|c|c|c|c|}
\hline \multirow[b]{2}{*}{$\begin{array}{l}\text { REDE PÚBLICA DE } \\
\text { EDUCAÇÃO }\end{array}$} & \multicolumn{2}{|c|}{2014} & \multicolumn{2}{|c|}{2015} \\
\hline & $\begin{array}{c}\text { PROJETOS } \\
\text { PREVISTOS } \\
\text { EDITAL } \\
\text { FAPEAM } \\
\text { N.029/2013 }\end{array}$ & $\begin{array}{c}\text { PROJETOS } \\
\text { APROVADOS } \\
\text { DECISÃO DO } \\
\text { CONSELHO } \\
\text { DIRETOR/ } \\
\text { FAPEAM } \\
\text { N. 062/2014 }\end{array}$ & $\begin{array}{c}\text { PROJETOS } \\
\text { PREVISTOS } \\
\text { EDITAL } \\
\text { FAPEAM } \\
\text { N.021/2014 }\end{array}$ & $\begin{array}{c}\text { PROJETOS } \\
\text { APROVADOS } \\
\text { DECISÃO DO } \\
\text { CONSELHO } \\
\text { DIRETOR/ } \\
\text { FAPEAM } \\
\text { N.117/2015 }\end{array}$ \\
\hline $\begin{array}{l}\text { SEDUC/SEMED } \\
\text { CAPITAL }\end{array}$ & 200 & 145 & 200 & 187 \\
\hline SEDUC INTERIOR & 120 & 140 & 220 & 143 \\
\hline TOTAL POR EDITAL & 320 & 334 & 420 & 429 \\
\hline $\begin{array}{l}\text { TOTAL DE PROJETOS } \\
\text { APROVADOS 2014/2015 }\end{array}$ & & & & \\
\hline $\begin{array}{c}\text { TOTAL DE PROJETOS } \\
\text { QUE ABORDAM } \\
\text { TEMÁTICA AMBIENTAL }\end{array}$ & - & 25 & - & 36 \\
\hline
\end{tabular}

Fonte: DITEC/FAPEAM, 2016. Elaborado pelos autores neste trabalho.

No período estudado, verificou-se um aumento (29\%) no número de projetos aprovados na edição de 2015 (Edital PCE FAPEAM N.021/2014), quando comparada à de 2014 (Edital PCE FAPEAM N.029/2013), e um aumento na demanda qualificada, considerando que o número de projetos aprovados nos dois editais foi superior ao estimado inicialmente (Tabela 1). Acredita-se que esse crescimento se deu devido ao aumento nos investimentos disponibilizados pela agência, considerando o sucesso do Programa em suas edições anteriores.

A oportunidade de financiamento desses projetos no âmbito escolar, proporcionada pelo PCE, permite aos professores da rede pública de ensino agregar a pesquisa às suas atividades didáticas e estimular a participação dos alunos neste tipo de iniciativa, envolvolvendo-os na construção do conhecimento e no desenvolvimento de senso crítico.

Nos relatórios, os professores registraram que os projetos melhoraram o ensino-aprendizagem na escola, desenvolveram o interesse e aumentaram a 
participação dos estudantes nas aulas, além de desenvolver o sentimento de pertencimento e a criticidade externados por esses estudantes ao longo das atividades desenvolvidas.

Santos (2013) afirma que a educação pela pesquisa se constitui em uma ferramenta pedagógica que contribui para a aprendizagem do aluno, fazendo com que o mesmo passe de sujeito passivo para ativo na construção do seu próprio conhecimento. Prado (2003) ressalta que existem, nos projetos, propostas e trabalhos interessantes, porém o desafio está em como conceber e tratar a articulação entre as suas instâncias, para que de fato seja construída na escola uma nova forma de ensinar, integrando as diversas mídias e conteúdos curriculares numa perspectiva de aprendizagem construcionista ${ }^{3}$. Para o autor, na pedagogia de projetos, o aluno aprende no processo de produzir, de levantar dúvidas, de pesquisar e de criar relações, que incentivam novas buscas, descobertas, compreensões e reconstruções de conhecimento. Mais que isso, verificamos neste estudo que a metodologia de projetos no âmbito do PCE permitiu, a partir de uma postura critica, que alguns alunos e professores se vissem como cidadãos que precisavam rever suas posturas em relação às questões ligadas ao meio ambiente.

De acordo com Pinheiro (2007), o papel inicial de práticas curriculares com interações entre ciência e tecnologia como esta é despertar no aluno a curiosidade, o espírito investigador, questionador e transformador de sua realidade, pois a pedagogia convencional, que em sua gênese tradicional oferece um sistema de separação entre alunos e professores, passaria por uma nova configuração, uma vez que professores e alunos assumiriam o mesmo patamar, passando a descobrir juntos, pesquisar, construir e reconstruir o conhecimento científico sob a ótica do trabalho em conjunto. Além disso, nesta perspectiva, como cidadãos, professores e alunos se vêem protagonistas da mudança necessária no cenário ambiental em que vivem e intervêm.

Dentre os 763 projetos aprovados nas duas edições, $7,5 \%$ deles, na edição de 2013, abordaram a temática ambental. Em 2014, houve um pequeno aumento $(1 \%)$ na proporção de projetos que abordaram essa temática (Figura 1).

Considerando que o PCE não delimita áreas do conhecimento em que os projetos devem ser desenvolvidos, ficando, assim, a critério do professor proponente decidir qual temática deseja abordar, verifica-se que, nos anos estudados, as questões ambientais não foram prioritárias dentre as temáticas abordadas. Mesmo identificando um aumento de $44 \%$ no número total de projetos aprovados em 2014, a temática ambiental foi abordada por menos de $10 \%$ deles (Figura 1 ).

${ }^{3}$ Construcionismo significa "a construção de conhecimento baseada na realização concreta de uma ação que produz um produto palpável (um artigo, um projeto, um objeto de interesse pessoal de quem produz" (Valente 1999 apud Prado 2003, p. 141). 


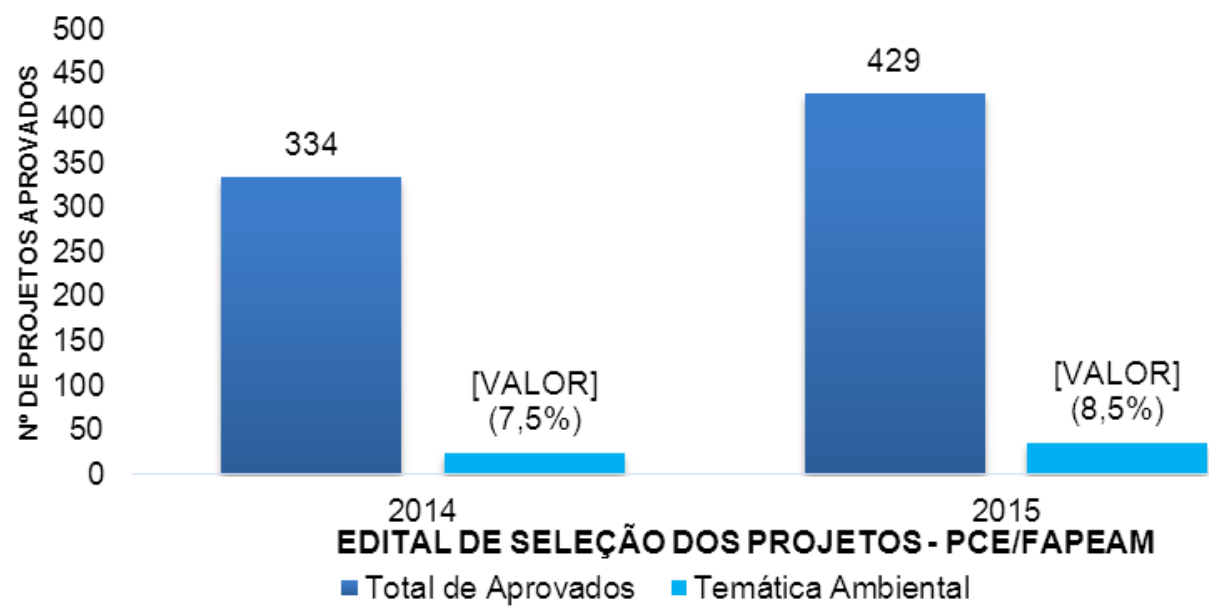

Figura 1: Número total de projetos aprovados no Programa Ciência na Escola - PCE/FAPEAM nos Editais FAPEAM N. 029/2013 e 021/2014 e número daqueles que abrodaram a temática ambiental.

Fonte: Diretoria Técnico-Cientifica - DITEC/FAPEAM, 2016. Elaborado pelos autores.

Dos 61 projetos que abordaram a temática ambiental, 51 foram desenvolvidos em escolas públicas da SEDUC (85\%) e outros 10 (15\%) em escolas vinculadas à SEMED. No ano de 2014, houve um aumento no número de projetos desenvolvidos nas escolas administradas pela SEDUC (Figura 2).

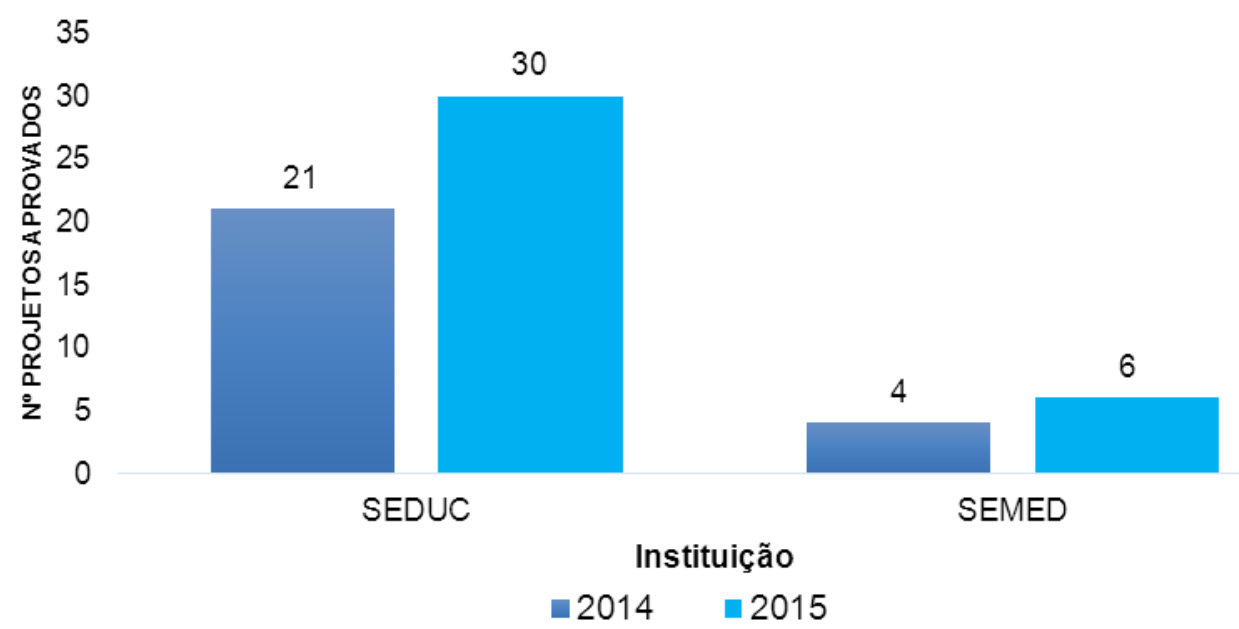

Figura 2: Número de projetos que abordaram a temática ambiental desenvolvidos em escolas das redes estadual e municipais de educação do Amazonas, no âmbito do PCE/FAPEAM/SEDUC/SEMED (Editais N. 029/2013 e 021/2014).

Fonte: Diretoria Técnico-Cientifica - DITEC/FAPEAM, 2016. Elaborado pelos autores. 
Em se tratando de níveis de ensino, grande parte dos projetos que abordaram a temática ambiental foi desenvolvida por professores e alunos do ensino médio (Tabela 2). Essa relação pode estar vinculada à maior participação das escolas administradas pela SEDUC, que é a instituição responsável pela oferta de ensino médio no Amazonas. Assim, $83 \%$ dos projetos aprovados foram desenvolvidos nessas escolas e a maioria deles (62,2 \%) na capital (Tabela 2).

Cenário similar foi registrado por Souza (2013) ao analisar as práticas de Educação Ambiental em duas escolas de Manaus, onde verificou o desenvolvimento de projetos de Educação Ambiental somente no âmbito de disciplinas do ensino médio. Os Parâmetros Curriculares Nacionais (PCNs) propõem o tema "Meio Ambiente" como uma abordagem transversal, devendo a Educação Ambiental ser tratada como um tema transversal, em todas as disciplinas, de todas as séries do Ensino Básico (BRASIL, 1998).

Tabela 2: Quantitativo de projetos que abordaram a temática ambiental por nível de ensino e área de abrangência. Projetos desenvolvidos nos anos de 2014 e 2015 em escolas das redes estadual e municipais de educação do Amazonas, no âmbito do PCE/FAPEAM/SEDUC/SEMED (Editais N. 029/2013 e 021/2014). N=61

\begin{tabular}{ccccc}
\hline \multirow{2}{*}{ ANO } & \multicolumn{2}{c}{ NIVEL DE ENSINO } & \multicolumn{2}{c}{ AREA DE ABRANGÊNCIA } \\
\cline { 2 - 5 } & FUNDAMENTAL & MÉDIO & CAPITAL & INTERIOR \\
\hline 2014 & 13 & 12 & 19 & 06 \\
2015 & 14 & 22 & 21 & 15 \\
TOTAL & 27 & $\mathbf{3 4}$ & $\mathbf{4 0}$ & 21 \\
\hline
\end{tabular}

Fonte: Diretoria Técnico-Cientifica - DITEC/FAPEAM, 2016. Elaborado pelos autores.

Lima (2011) afirma que EA escolar tem características próprias e se constituiu no amálgama do campo da EA e de conhecimentos das disciplinas escolares, especialmente em ciências e geografia. Não diferente do que é apresentado pela autora, as disciplinas que se destacaram no desenvolvimento dos projetos do Programa PCE, no período analisado, foram biologia, geografia e ciências (Figura 3 ). 


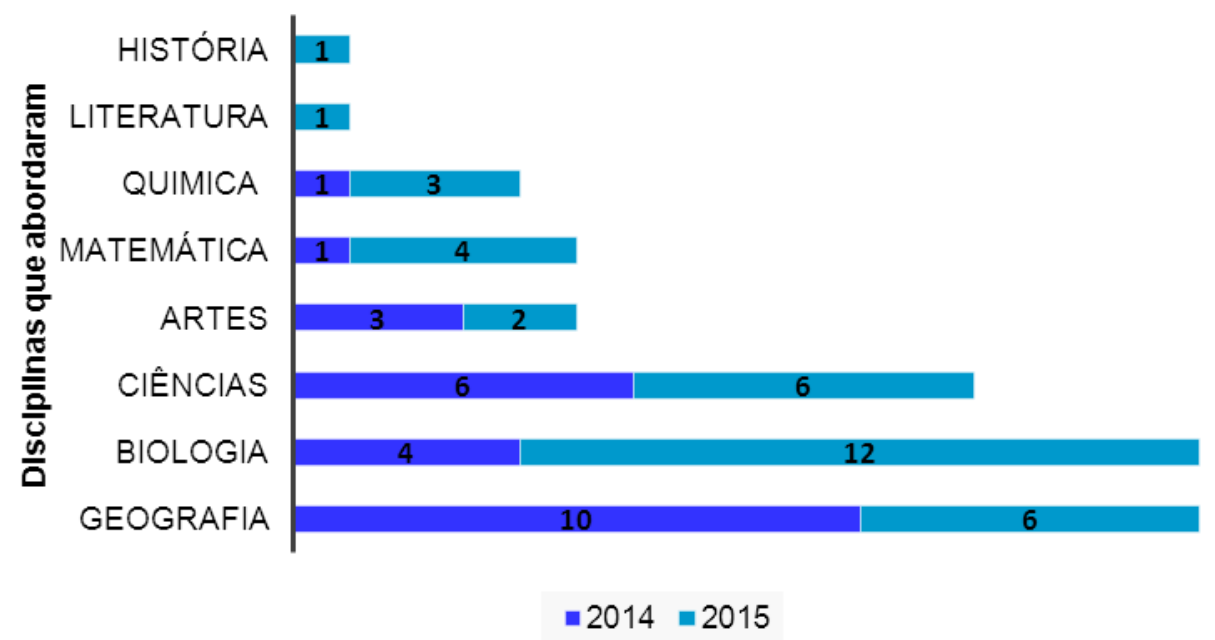

Figura 3: Número de projetos que abordadaram a temática ambiental desenvolvidos no âmbito do PCE, Editais FAPEAM N. 029/2013 e n. 021/2014. $\mathrm{N}=61$.

Fonte: Diretoria Técnico-Cientifica - DITEC/FAPEAM, 2016. Elaborado pelos autores.

No ano de 2015, o maior número de professores desenvolveu projetos vinculados às disciplinas de biologia (12 projetos), geografia (6) e ciências (6), enquanto que em 2014 foram geografia (10), ciências (6) e biologia (4). Quando comparadas as duas edições, verifica-se uma redução no número de projetos desenvolvidos nas disciplinas de geografia e artes e um aumento em biologia, matemática e química. Projetos envolvendo a temática ambiental, desenvolvidos nas disciplinas história, educação física e literatura, ocorreram somente em 2015 e em pequenas proporções (Figura 3).

Almeida (2007) também verificou que a abordagem da EA estava mais presente nas disciplinas de ciências da natureza e geografia e atribui a maior abordagem da EA nessas disciplinas a três fatores: (1) maior ligação dos assuntos das ciências da natureza à temática ambiental; (2) o conhecimento da natureza proporcionado por estas ciências; e (3) a sintonia dos processos científicos com algumas finalidades da EA.

A baixa frequência da aboradagem da temática ambiental nas demais disciplinas reforça fatores apresentados por Trajber e Mendonça (2006) e Almeida (2007) e evidencia que a EA ainda não se apresenta de modo transversal nas disciplinas e sim atrelada aos conteúdos. Este fato neste estudo em específico, é reforçado por um dos Critérios de Seleção e Avaliação (item 7. dos Editais) dos projetos apresentados ao PCE, que consistia em: "7.1. Tema da pesquisa compatível com o conteúdo programático da série dos alunos que serão bolsistas do projeto $\mathrm{e}$ com as disciplinas ministradas pelo professor/coordenador", o que pode ter induzido ao quadro de disciplinas aqui revelado. 
As disciplinas ciências, biologia e geografia são tratadas e aceitas historicamente, no âmbito formal de ensino, como as maiores portadoras de temas e meios referentes à EA, seja em função da comum associação direta entre as representações sociais sobre ambiente e os conteúdos próprios de tais disciplinas, seja em função do envolvimento tradicional desses profissionais e de suas instituições em assuntos que versam sobre a temática ambiental (TRAJBER; MENDONÇA, 2006).

Dias (1998) adverte que há necessidade de separar a Educação Ambiental da ecologia. O autor defende o enfoque interdiscilinar da EA de modo que os assuntos não fiquem confinados a uma dimensão estritamente ecológica. Figueiredo e Farbelow (2018), por sua vez, reforçam que a Educação Ambiental ainda não atingiu a prática interdisciplinar, sendo ainda bastante conteudista, porém defendem que, por meio da pesquisa-ação-participante e do princípio da dialética como ferramentas, a Educação Ambiental, para serefetiva, precisa ser implementada paulatinamente.

Além de a abordagem da temática ambiental se concentrar nos projetos desenvolvidos nas disciplinas de ciências, biologia e geografia, verifica-se uma diversidade de visões acerca dos conceitos de EA que resultam em diferentes formas de abordá-la, cada uma delas envolta em concepções pedagógicas de educação e compreensões distintas do que é meio ambiente. O que mais se evidencia são projetos que relacionam a Educação Ambiental a ações voltadas ao cuidado com os recursos naturais ou àquelas vinculadas à preocupação com a produção de resíduos sólidos. Essas abordagens se aproximam respectivamente das macrotendências pedagógicas conservacionista e pragmática apontadas por Layrargues e Lima (2014). Mesmo fora da escola, as abordagens mais frequentes nos Planos de Manejo de Unidades de Conservação paulistas também utilizam em grande maioria elementos das macrotendencias consevacionista e pragmática (RODRIGUES et al,. 2018).

Nos projetos desenvolvidos nas duas edições do PCE (2014 e 2015), os temas mais abordados foram: reciclagem (28\%), lixo (21\%), compostagem e água (com 10\% cada) (Figura 4). 


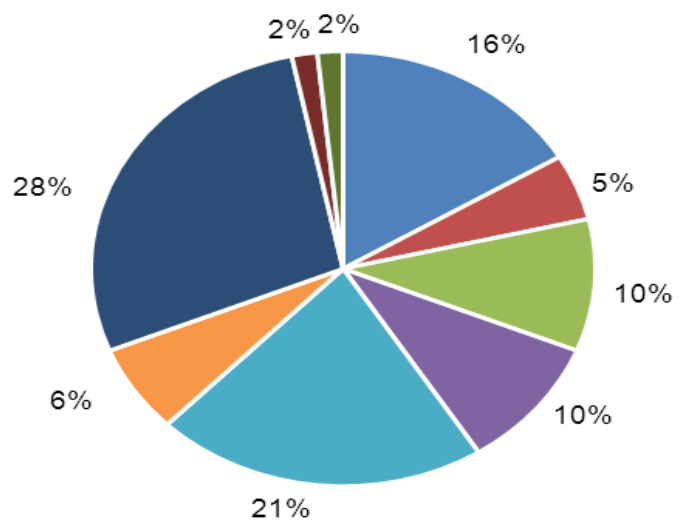

- Questões Ambientais

- Rearborização

- Água

- Compostagem

- Lixo

- Horta

- Reciclagem

- Coleta Seletiva

- Queimada

Figura 4: Temáticas abordadas nos projetos aprovados no Programa PCE: Edital FAPEAM N. 029/2013 e 021/2014.

Fonte: Diretoria Técnico-Cientifica - DITEC/FAPEAM, 2016. Elaborado pelos autores.

Existe um conjunto de projetos que abordam questões ambientais (16\%) num contexto diverso e difuso, caracterizando-se como ações de sensibilização dos alunos para a problemática ambiental esperando mudanças de atitude a partir do conhecimento desta realidade. Segundo Morales (2012), é recorrente nas falas dos professores o objetivo de mudar comportamentos individuais, como se fosse suficiente para produzir as profundas transformações necessárias e rever a situação atual.

Ao analisar os projetos nas diferentes modalidades de ensino, vimos que grande parte deles foi desenvolvida com alunos do ensino médio. Nessa modalidade de ensino, os temas mais trabalhados foram lixo, reciclagem, questões ambientais (denominação dada aos projetos que trataram de temas variados) e compostagem. Já na modalidade do ensino fundamental, os temas mais trabalhados foram reciclagem, lixo e compostagem (Figura 5).

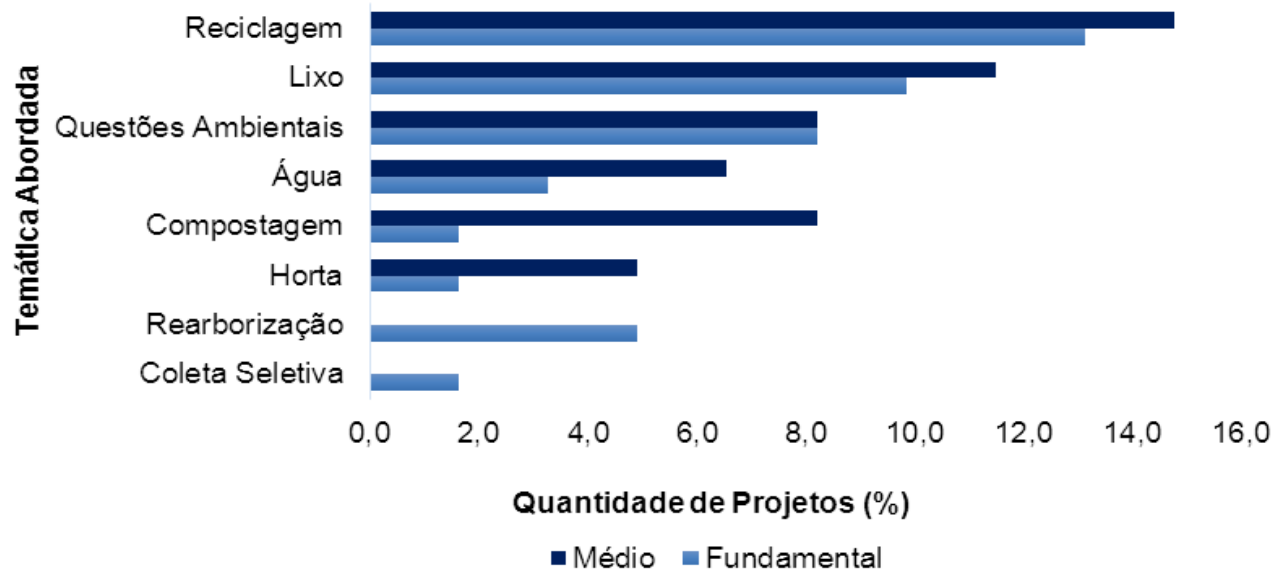

Figura 5: Temáticas abordadas nos projetos aprovados no Programa PCEFAPEAM/SEDUC/SEMED (Edital FAPEAM N. 029/2013 e 021/2014) por Modalidade de Ensino. Fonte: Diretoria Técnico-Cientifica - DITEC/FAPEAM, 2016. Elaborado pelos autores. 
Tajber e Mendonça (2006) verificaram que as pricipais temáticas indicadas para o desenvolvimento da Educação Ambiental em escolas brasileiras foram água, lixo e reciclagem. Na mesma pesquisa, analisando os estados do Pará e Amapá, identificaram que as principais temáticas trabalhadas em ações de Educação Ambiental nestes estados foram: a) água; b) poluição e saneamento básico; e c) lixo e reciclagem. Em levantamento realizado em escolas brasileiras, Moraes (2012) pondera que as escolas possuem uma visão pouco problematizada da EA, sendo traduzida em práticas educativas equivocadas geralmente relacionadas exclusivamente à reciclagem.

Desta forma, observamos que os interesses pelos temas pouco mudaram em uma perspectiva de análise dos problemas socioambientais. Verificando as temáticas abordadas nos projetos desenvolvidos no PCE nos anos de 2014 e 2015, identificamos que a presença da temática ambiental no âmbito escolar está orientada para desenvolver nos alunos a preocupação com as questões ambientais, de forma a despertar inquietações que os levem à busca por possíveis soluções a fim de reverter o quadro atual.

Neves et al. (2014) dizem que a temática ambiental deve ser desenvolvida no contexto educacional levando em consideração os aspectos ambientais em que a escola está inserida, buscando, desta forma, um processo de conscientização ambiental que gere ações para manter um meio ambiente ecologicamente equilibrado.

Diante desses dados, inquietou-nos querer compreender quais fatores motivaram esses professores a trabalharem tais temáticas. Seriam os problemas ambientais divulgados na mídia? Ou a realidade na qual a escola está inserida? $\mathrm{Ou}$, ainda, os problemas enfrentados pelo município, bairro ou comunidade onde alunos e professores viviam?

Independentemente da localização geográfica das escolas e os municípios onde estão inseridas (capital/interior), o tema lixo e seus desdobramentos (reciclagem e compostagem) foram os mais recorrentes entre os projetos (Figura 6). Para Miranda (2002), o lixo é um dos grandes problemas ambientais urbanos, constituindo-se uma preocupação ambiental mundial.

Verificou-se, nos projetos, que essa problemática é uma preocupação tanto nos centros urbanos como nas localidades do interior, considerando o crescimento desordenado, que é uma característica das cidades, e a ausência de serviços de coleta de lixo nas comunidades rurais amazônicas. Segundo Higuchi et al. (2009), os municípios da Amazônia possuem graves problemas ambientais a serem equacionados e enfrentados, tanto nas áreas urbanas, quanto nas rurais. De acordo com os autores, um dos problemas pertinentes nas áreas urbanas é o lixo.

Uma temática abordada somente na capital foi a coleta seletiva, que é um tema discutido em muitos centros urbanos. Richter (2014) descreve que a coleta seletiva assume importante papel no que diz respeito à preservação do meio ambiente, tornando-se uma saída viável para evitar que este resíduo seja 
destinado aos lixões. No entanto, de acordo com a autora, afirmando o que foi diagnosticado nesta pesquisa, esta não é uma prática comum em cidades menores.

Estudos realizados por Caldeira (2012), em escolas do município de Ponta Grossa, também apontaram que a temática reciclagem e coleta seletiva é adotada com bastante frequência no ambiente escolar, porém pauta-se por vezes numa atitude isolada, sem que seja dada a devida importância na discussão sobre a produção de consumo e sustentabilidade, questões fundamentais para se oportunizar a construção de valores ambientais, o que poderia, dessa forma, resultar na mudança de hábitos e atitudes dos alunos.

Merece destaque, também, o fato de que a temática queimada foi abordada somente nos projetos desenvolvidos no interior. Esse tema é bastante comum nas áreas rurais de municípios do Amazonas, onde muitos moradores costumam queimar seu lixo doméstico, pela falta de coleta pública ou até mesmo pela cultura da queima do lixo nos quintais. Outro fator preocupante, e que pode ser um dos influenciadores para abordar este tema, é o aumento anual de queimada na Amazônia (GONÇALVES et al., 2012), que geralmente ocorre após o desmatamento. Higuchi et al. (2009) ressaltam que os desmatamentos irregulares nas áreas rurais da Amazônia são muito comuns.

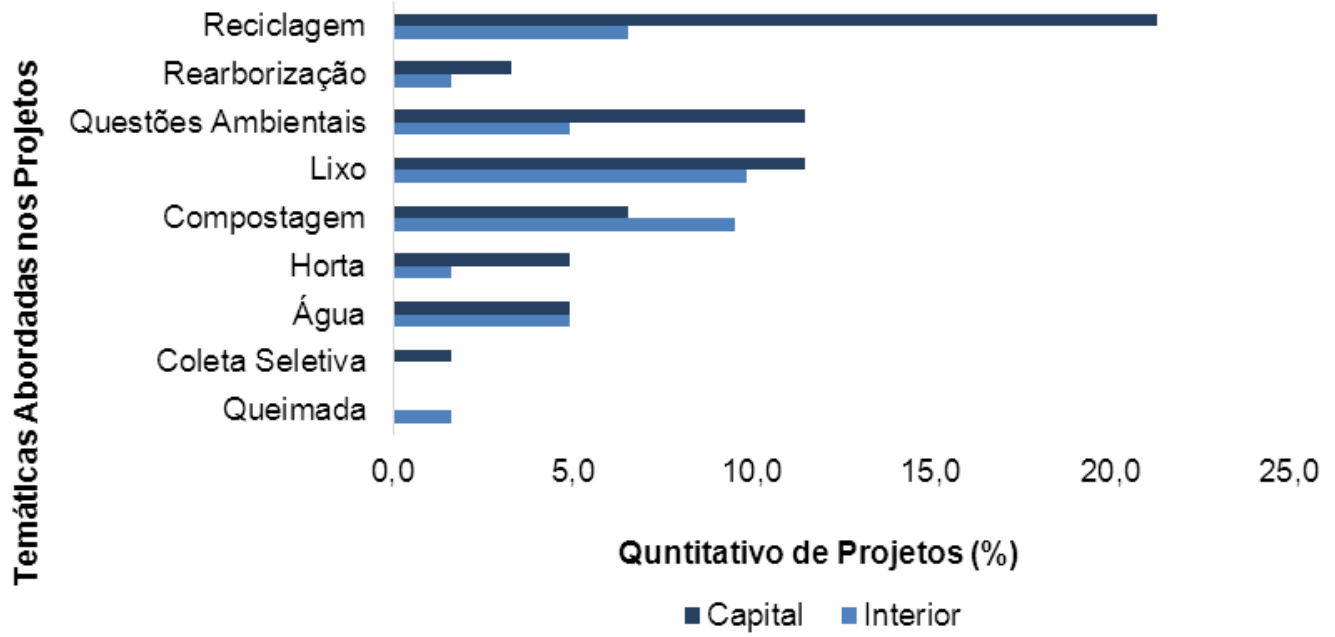

Figura 6: Temáticas abordadas nos projetos aprovados no Programa PCE-

FAPEAM/SEDUC/SEMED (Edital FAPEAM N. 021/2013 e 029/2014) na capital e no interior.

Fonte: Diretoria Técnico-Cientifica - DITEC/FAPEAM, 2016. Elaborado pelos autores.

Neste sentido, entendemos que a crise ambiental que estamos vivendo é reflexo de uma relação cada vez mais predatória que o homem passou a ter com a natureza. Daí a recomendação de abordagem mais frequente da temática ambiental no dia-a-dia das escolas. Mesmo após a PNEA, no final dos anos 90, que determina uma abordagem transversal do tema "Meio Ambiente", em todas as disciplinas, de todas as séries do Ensino Básico, verifica-se que pouco se avançou nesse período. Mesmo quando há incentivo financeiro para a 
elaboração de projetos, a temática ambiental não é o foco desses trabalhos, representando menos que $10 \%$ do total de 763 projetos apoiados pelo PCE nos anos de 2014 e 2015, os quais foram, em sua maioria, desenvolvidos no ensino médio e nas disciplinas geografia, ciências e biologia.

\section{Conclusão}

A partir deste estudo, foi possível compreender como a Educação Ambiental vem sendo trabalhada em escolas públicas da capital e interior do Amazonas tendo como "lente" o Programa Ciência na Escola - PCE. Considerando que não há direcionamento para uma área específica, ficando a critério do professor escolher a temática a ser trabalhada, verifica-se que a temática ambiental não está entre os temas prioritários para ser abordado em projetos por professores da rede pública de ensino do Amazonas. Mesmo sendo um assunto pertinente na atualidade, sua abordagem ainda se mostra tímida, pois, nas duas edições, somente $8 \%$ dos projetos desenvolvidos em escolas da capital e interior abordaram temas relacionados às questões ambientais. Lixo, reciclagem, água e compostagem continuam sendo os temas mais frequentes nos projetos desenvolvidos em escolas públicas desde 2006.

Ainda que em baixa proporção, a maior parte desses projetos foi desenvolvida por professores e alunos do ensino médio de escolas administradas pela Secretaria de Estado de Educação (SEDUC). Fica evidente, também, que a EA ainda não se apresenta de modo transversal nas disciplinas e sim atrelada aos conteúdos e continua a ser mais frequente nas disciplinas ciências, biologia e geografia, onde verifica-se maior ligação dos conteúdos abordados nessas disciplinas com a temática ambiental.

Isso nos fez refletir que, mesmo quando temos uma Politica Nacional que determina a abordagem da EA nas escolas como componente essencial e permanente da Educação, os docentes que desenvolveram projetos no âmbito do PCE ainda não estão priorizando a temática ambiental e tampouco abordando essa temática em todas as disciplinas e modalidades de ensino da educação básica.

Um aspecto positivo regstrado neste estudo foi a mudança na postura de alguns professores coordenadores de projetos, que deixaram de ser transmissores de informações para criar situações de ensino-aprendizagem baseadas nas relações e análise de problemas ambientais locais. Em alguns projetos, verificou-se ainda que o processo foi importante para a mudança de postura tanto do aluno quanto do professor, em relação ao ambiente. 


\section{Referências}

ALMEIDA, A. Qua papel para as Ciências da Natureza em Educação Ambiental? Discussão de idéias a partir de resultados de uma investigação. Reviste Eletrônica de Enseñanza de las Ciencias, v. 6, n. 3, p.522-537. 2007. Obtido em http://reec.educacioneditora.net/

BRASIL. A Implantação da Educação Ambiental no Brasil. Coordenação de Educação Ambiental. Ministério da Educação e do Desporto, Brasília, DF, 1998.

BRASIL. Resolução CONAMA no 306, de 5 de Julho de 2002. Definição de Meio Ambiente. Brasília, DF, jul 2002. Disponível em: http://portal2.tcu.gov.br/portal/pls/portal/docs/2054922.pdf. Acesso: 10/12/2016.

BRASIL. Educação na diversidade: o que fazem as escolas que dizem que fazem Educação Ambiental/Organização: Rachel Trajber, Patrícia Ramos Mendonça. - Brasília: Secretaria de Educação Continuada, Alfabetização e Diversidade, 2006.

BRASIL. Resolução № 2, de 15 de Junho de 2012. Estabelece as Diretrizes Curriculares Nacionais para a Educação Ambiental. Brasília, DF, 2012. Disponível em: <http://portal.mec.gov.br/index.php?option=com docman\&view= download\&alias=10988-rcp002-12-pdf\&category slug=maio-2012pdf\&ltemid=30192>. Acesso em: 20 jan.2016.

CALDEIRA, C. S.; NUNES, A. L. R.; MORALES, A. G. Mapeamento dos projetos de Educação Ambiental no ensino fundamental. Anais do Seminário de Pesquisa em Educação da região Sul - IX ANPED SUL. Caxias do Sul. 2012.

CUBA, M. A. Educação Ambiental nas escolas. ECCOM, v. 1, n. 2, p. 23-31, jul./dez. 2010.

DEMO, P. Educação e Alfabetização Científica. Rio de Janeiro: Papiros, 2010.

FIGUEIREDO, R. A.; F, M. V. A didactical approach proposition in environmental education in a brazilian higher education context. Revista Brasileira de Educação Ambiental, São Paulo, v. 13, n. 1,108-123. 2018.

GIL, A.C. Métodos e técnicas de pesquisa social. 5ed. São Paulo: Atlas, 2010. GONÇALVES, K. S.; CASTRO, H. A.; HACON, S. S. As queimadas na região amazônica e o adoecimento respiratório. Ciência \& Saúde Coletiva, v. 17, n. 6, 1523-1532. 2012.

HERNANDEZ, F. Transgressão e Mudança na Educação: Os Projetos de Trabalho. Tradução Jussara Haubert Rodrigues. Porto Alegre: Artes Médicas Sul, 1998.

HERNANDEZ, F.; VENTURA, M. Os projetos de trabalho: uma forma de organizar os conhecimentos escolares. O conhecimento é um caleidoscópio. Porto Alegre: Artes Medicas, 1994.

HIGUCHI. N.; PEREIRA, H. S.; SANTOS, J.; LIMA, A. J. N; HIGUCHI, F. G.; HIGUCHI, M. I. G.; AYRES, I. G. S. S. Governos locais amazônicos e as questões climáticas globais. 86p. Manaus, 2009. 
LIMA, M.J. G. S. A disciplina Educação Ambiental na Rede Municipal de Educação de Armação de Búzios (RJ): investigando a tensão disciplinaridade/integração na política curricular. Tese de doutoramento apresentada na Faculdade de Educação da UFRJ. Rio de Janeiro - RJ. 2011.

MIRANDA, J. C. A coleta seletiva e reciclagem de lixo na escola: uma atividade prática. In: Anais do VIII EPEB - Biologia e cidadania: contextos de ensino e produção científica, São Paulo. 2002.

MORAES, P. C. Educação Ambiental crítica: uma experiência na formação inicial de professores. Nilópolis, RJ. 70f. Dissertação (Mestrado Profissional em Ensino de Ciências); IFAM, Rio de Janeiro. 2012.

MORALES, A. G. A formação do profissional educador ambiental: reflexões, possibilidades e constatações. 2 ed. 223p. 2012.

NEVES, M. J. C.; OLIVEIRA, M. C.; OLIVEIRA, G. F. P.; OLIVEIRA, G. J. A Temática Ambiental nas práticas pedagógicas das escolas públicas de $3^{\circ}$ ano de Ensino Médio de Parnaíba - Pi. Anais do V ENEBIO e II EREBIO Regional 1. Revista da SBEnbio. n.7. 2014.

NOGUEIRA, A. C. F.; SANSON, F.; PESSOA, K. A expansão urbana e demográfica da cidade de Manaus e seus impactos ambientais. Anais XIII Simpósio Brasileiro de Sensoriamento Remoto, Florianópolis, Brasil, 21-26 abril. INPE, p. 5427-5434. 2007.

PRADO, M. Pedagogia de Projetos. Série "Pedagogia de Projetos e Integração de Mídias" - Programa Salto para o Futuro. Setembro. 2003.

PINHEIRO, N.A.M. SILVEIRA,R.M.C.F. BAZZO, W. Ciência, Tecnologia e Sociedade: a relevância do enfoque CTS para o contexto do ensino médio. Ciência \& Educação. v.13, n. 1, p.71-84. 2007.

REIGOTA, M. O que é Educação Ambiental. São Paulo: Brasiliense. 1994.

RICHTER, L. T. A importância da conscientização e da coleta seletiva no município de Palmitos - SC. Monografia. UTFPR. 2014.

RODRIGUES, L. M.; CAMPANHÃO, L. M. B.; BERNARDI, Y. R. Tendências político-pedagógicas de Educação Ambiental em unidades de conservação: o caso dos parques estaduais de São Paulo. Revista Brasileira de Educação Ambiental, São Paulo, v. 13, n. 1,192-212. 2018.

SANTOS, J. A. M. Investigação do uso da educação pela pesquisa na prática pedagógica de professores de química da educação básica. Universidade Federal de Campina Grande. Anais do 5ํㅡㄹ Congresso Norte Nordeste de Química. 3ํㅡㄹ Encontro Norte-Nordeste do ensino de Química. 8 -12 abril. 2013

SOUZA, F.H.C. A escola como espaço de (in) coerências: a prática da Educação Ambiental para formação de sociedades sustentáveis em duas escolas do município de Manaus. 151 f. Dissertação (Mestrado em Ciências do Ambiente). Universidade Federal do Amazonas, Manaus - AM. 2013. 